\title{
The impact of ICT investments on human development: a regression splines analysis
}

Felix Olu Bankole, Kweku-Muata Osei-Bryson and Irwin Brown

\begin{abstract}
Despite the worldwide growth in investments in information and communication technology (JCT), few studies have investigated the complex interactions between components of JCT investments and different dimensions of human development. The purpose of this study is to explore the conditional impacts of JCT investments (Hardware, Software, Internal Services Spending and Telecommunication) on two dimensions of Human Development (Standard of Living and Health) within three contexts (classified as High, Medium and Low income countries). To carry out the study, archival data concerning JCT investments and human development for 51 countries with the largest JCT markets were collected for the period 1994 to 2003. The study utilized a novel approach called regression splines to analyse the data. Results suggest, among other things, that: (1) the impact of investments in the different JCT components varies with context; (2) impacts are in many cases conditional and complex; and (3) the direction of impacts of JCT investment on Standard of Living may be different from the corresponding directions of impacts on Health. It is therefore necessary for policy makers or IS executives to do in-depth tradeoff analysis between the different components of JCT investment to determine appropriate allocations.
\end{abstract}

\section{Introduction}

In recent decades, investments in information and communication technology (JCT) have grown substantially in both developed and developing countries (Qiang \& Pitt, 2004; WITSA, 2008; Bollou \& Ngwenyama, 2008; Shiraz, 2010). This rapid growth has brought digital opportunities to many countries, yet it is not clear whether the impacts on national development of different components of ICT investment are the same for countries at different levels of economic maturity (Samoilenko \& Osei- Bryson, 2008a and b; Kim et al., 2008; Morawczynski \& Ngwenyama, 2007). The notion of development is often ill-defined in many studies concerned with ICTs and national development. One component of development is human development and to avoid ambiguity, this study uses the concept of human development as defined by UNDP (2003). Human development (HD) is considered to be "the process of enlarging people 's choices", particularly with regards to choices available for leading "a long and healthy life",acquiring knowledge (education), and having "access to the resources needed for a decent standard of living" (UNDP, 2003). The two dimensions focused on 
in this study are health and standard of living, as they are more likely impacted by ICT investments in the short-term than education.

The nature of the relationships between different components of ICT investment and dimensions of human development is not fully understood (Kim et al. 2008). Investments in ICT can be classified as: hardware investments, software investments, telecommunication investments, and internal services spending (e.g., training and human capital development) (WITSA, 2008). It is recognised that these ICT components are not the only determinants of country-level performance with respect to human development. For example, it is reasonable to expect that other factors, such as the quality of the healthcare system, and the availability and affordability of appropriate nutrition and medication would have a significant impact on health outcomes. Similarly, with regards to Standard of Living, there are multiple factors apart from ICT, including material conditions (e.g., quality of the transportation network), quality of the workforce, and the legal and economic environment that may have a significant impact. The aim of this study, however, is to focus specifically on the impact of ICT investments on human development.

Prior studies such as Kim et al. (2008) have explored the impacts of information technology investments (i.e., Software, Hardware, and Internal Services Spending) on standard of living (GDP per capita) in varying contexts. Others such as Bankole et al. (2011) examined the impacts of ICT investments on human development (GDP per capita, Education attainment and Life expectancy) in varying contexts. Although, both studies demonstrated that components of ICT investment have a positive impact on different dimensions of human development, the conditions of such impact are not known. This study is an attempt to expose those conditions. Consequently the research question asked is: What are the conditional impacts of JCT investments on human development, in varying contexts?

Many studies investigating the impact of ICT investments on development have employed simple regression analysis. Such analyses are limited when the impact of an independent variable on a dependent variable is conditional. Regression splines is an approach that can identify such conditions (Ko \& Osei-Bryson, 2004) and wasemployed in this study.

The rest of this article is organised as follows: The next section provides an overview of the literature, followed by a presentation of the conceptual framework. The research methodology follows, after which the results of the regression splines are presented. The implications of the findings for research and practise are highlighted, followed by the summary and conclusion.

\section{Conceptual background \\ ICT investments}

ICT investments can be categorized as annual spending on hardware (H), software (S), telecommunications equipment (T) and internal IT services (ISS) (e.g., ICT workers and professional services) (Oulton, 2002; WITSA, 2008; Kim et al., 2008, Bankole et 
al., 2011). These measures of ICT investments allow for country-level comparisons to be made across years. For the purposes of this study:

I. Computer Software Investments are the total annual value of all purchased software products including software packages, database systems, application tools, utility software and programming tools in a country (WITSA, 2008).

IL Computer Hardware Investments refer to the total annual computer hardware spending in a country. It includes purchased or leased computers, storage devices, memory upgrades, printers, monitors, scanners, input-output devices, terminals and other peripherals from external agents ( WITSA, 2008; Kim et al., 2008)

1. Internal Services Spending (ISS) refers to the amount spent in a country on internal software customization, capital depreciation, human capital development and other IT related services (e.g., Outsourced domestic or offshore IT consulting, systems integration and facilities management).

2. Telecommunications Investments are the total annual amount invested in a country on wired or wireless communications and equipment (e.g., Wide Area Network or Local Area Network equipment) in a country (ITU, 2007; Samoilenko \& Osei-Bryson, 2008).

Components of ICT investment do not operate in isolation. It is known, for example, that computer Hardware cannot be effective without appropriate installed software and vice versa. This software could be externally developed (Software) or internally developed (Internal Services Spending). Spending on externally developed software may in some cases be more efficient and effective than spending on internally developed software. In other cases, there may be the need for internally developed. software (Internal Services Spending) to customize externally developed software. Thus in some cases external developed software may be a substitute for internal developed software; in other cases the relationship between the two could be complementary.

While some studies have explored the impacts of pair wise interactions of investments in Hardware, Software and Internal Services Spending on GDP (e.g., Kim et al., 2008), they have typically excluded an exploration of the impact of the interaction of Telecommunications and the other ICT components. Studies that have included telecommunications as a factor have typically looked at its impact on economic development in isolation, without reference to the other ICT components (WoldeRufael, 2007; Beil et al., 2005).

\section{Human development}

The state of human development reflects the quality of life in a nation based on three components: Standard of Living, Knowledge Acquisition, and Health. For assessing standard of living, gross domestic product per capita (GDP per capita) is often used; for knowledge acquisition capability (education), national literacy rates and levels of school enrolment are used; and for health, Infant mortality rate (IMR) and/or longevity (life expectancy at birth) are typically used (UNDP, 1990, 2006).

In this study, the focus is on the impact of ICT investments on the Standard of Living and Health dimensions of HD. The choice of these two dimensions is motivated by the 
fact that the impacts of ICT investments on these dimensions are more apparent in the short-term. For the Standard of Living dimension, GDP per capita is used as an indicator, commensurate with other similar studies (e.g., Morawczynski \& Ngwenyama, 2007). For the Health dimension, previous similar studies have tended to use Life Expectancy Rate (LER) as the indicator (e.g., Ngwenyama et al., 2006). A parallel measure of Infant Mortality Rate (IMR) may also be used. The advantage of the latter measure is that $M R$ is more likely than $L E R$ to be impacted in the short-term by ICT investments than LER. For example, major reasons for infant mortality (IM), especially in developing countries, include dehydration, diarrhoea and pneumonia. The dissemination of information to mothers on preventative and curative methods can result in a significant decrease in infant mortality (BMJ, 2012). ICTs can be used to facilitate the distribution of such information and to support other aspects of patient care management. Also, IMR is a widely used proxy for the health status of a nation and for international comparisons (Heisler, 2012). Since IMR is the number of infant deaths (one year of age or younger) per 1000 live births, then a parallel measure is the infant survival rate (ISR), where ISR $=(1000-$ IMR $)$. We will use ISR in this study, as it is a better indicator of health than IMR, which reflects poor health in a nation.

\section{Impact of ICT investments on human development}

ICT investments are referred to as second-order investments that, for example, create opportunities for people to overcome conditions of poverty and marginalization (Servon, 2002; Morawczynski \& Ngwenyama, 2007). International organizations such as the International Telecommunication Union (ITU), World Bank and International Monetary Fund (IMF), among others, have highlighted ICT as a tool with the potential to assist development in poor nations. For example, it can be used to rationalize the delivery of services, including health care delivery services to expectant and nursing mothers and to facilitate communication between patients and the health care system. It can be used to improve the management of government, public utilities (e.g., mass transit, water delivery), and enable and empower business organizations including small and medium enterprises. There have been protests from some quarters, however, that poor nations should be utilizing their limited resources on basic amenities like building schools and making provision for basic health, electricity and clean water, rather than ICT infrastructure (Ngwenyama et al., 2006; Morawczynski \& Ngwenyama, 2007). In any case, investigations on the impact of ICT investments on human development have been receiving attention among policy makers, ICT practitioners and governments (UNDP, 2003). 
Table 1. Specific Research and Findings from Key Studies

\begin{tabular}{|l|l|}
\hline \multicolumn{1}{|c|}{ Title, Author and Year } & \multicolumn{1}{|c|}{ Findings } \\
\hline $\begin{array}{l}\text { Are ICT Investments Paying Off in Africa? An } \\
\text { Analysis of Total Factor Productivity in Six West } \\
\text { African Countries from 1995-2002 (Bollou \& } \\
\text { Ngwenyama, 2008) }\end{array}$ & $\begin{array}{l}\text { ICT improved total factor productivity } \\
\text { in African countries. }\end{array}$ \\
\hline $\begin{array}{l}\text { Differential effects of IT Investments: } \\
\text { Complementarity and the effect on GDP Level } \\
\text { (Kim et al. 2008). }\end{array}$ & $\begin{array}{l}\text { The research indicates the ICT is an } \\
\text { important factor for improving GDP in } \\
\text { varying contexts. }\end{array}$ \\
\hline $\begin{array}{l}\text { Investments in ICT and its payoff in Malaysia } \\
\text { (Kuppusanmy \& Santhapparay, 2005) }\end{array}$ & $\begin{array}{l}\text { ICT investments are paying off in terms } \\
\text { of economic development. }\end{array}$ \\
\hline $\begin{array}{l}\text { Is there a Relationship between ICT, Health, } \\
\text { Education and Development? An Empirical }\end{array}$ & $\begin{array}{l}\text { There are statistically significant } \\
\text { relationships between investments in } \\
\text { Analysis of Five West African Countries. } \\
\text { ICT, health, education and levels of } \\
\text { hgwenyama, Ando-Baidoo, Bollou \& development. } \\
\text { Morawczyski, 2006). }\end{array}$ \\
\hline $\begin{array}{l}\text { An Exploration of the Effect of the Interaction } \\
\text { between ICT and Labor Force on Economic } \\
\text { Growth in Transition Economies (Samoilenko, \& } \\
\text { Osei-Bryson, 2008). }\end{array}$ & $\begin{array}{l}\text { Complementary investments in ICT } \\
\text { and labour are prerequisites for the } \\
\text { translation of ICT into macroeconomic } \\
\text { outcomes. }\end{array}$ \\
\hline $\begin{array}{l}\text { ICT Investments and Economic Growth in 1990s: } \\
\text { Is the United States a Unique Case? (Colecchia \& } \\
\text { Schreyer, 2002). }\end{array}$ & $\begin{array}{l}\text { ICT is contributing to economic growth } \\
\text { in the US and nine other OECD } \\
\text { countries. }\end{array}$ \\
\hline
\end{tabular}

Typically studies in this domain have investigated the economic impact of ICT investments (Jalava \& Pohjola, 2002; Daveri, 2002). Generally, findings point to the positive influence of ICT investment on economic development across a range of different contexts, but particularly in developed and newly developed nations (Oulton, 2002, Colecchia \& Schreyer, 2002; Kuppusamy \& Santhapparaj, 2005). Less research has investigated these impacts in developing and least developed countries (Mbarika et al., 2005). There are even fewer studies looking at the impact of ICT investments on other facets of human development, such as education and health (Ngwenyama et al., 2006). Few studies also disaggregate JCT investments into component parts (Kim et al., 2008). Table 1 shows specific research and findings from a sample of key studies.

The studies in Table 1 reflect the conventional wisdom concerning impacts of JCT investments on development. Few studies have looked at the conditional impacts of JCT investment components on dimensions of human development in varying contexts. This study aims to fill this research gap.

\section{Conceptual framework}

The conceptual framework considered is a translog production function framework (Ko \& Osei-Bryson, 2004; Berndt \& Christensen, 1972) of neoclassical Solow's model which allows for pairwise interactions between the components of ICT. It can be considered to have the following form where (D) represents one of the human development (HD) dimensions, (H) represents computer hardware investments, (S) represents computer 
software investments, (ISS) represents internal services spending and (T) represents telecommunications investments. This is expressed as:

$$
\begin{aligned}
& \log (\mathrm{D})=\alpha_{0}+\alpha_{\mathrm{HS}} \log (\mathrm{H}) * \log (\mathrm{S})+\alpha_{\mathrm{HI}} \log (\mathrm{H})^{*} \log (\mathrm{ISS})+\alpha_{\mathrm{SI}} \log (\mathrm{S}) * \log (\mathrm{ISS}) \\
& +\alpha_{\mathrm{TI}} \log (\mathrm{T})^{*} \log (\mathrm{H})+\alpha_{\mathrm{TI}} \log (\mathrm{T})^{*} \log (\mathrm{S})+\alpha_{\mathrm{TI}} \log (\mathrm{T})^{*} \log (\mathrm{ISS})+\xi
\end{aligned}
$$

The model for the above expression reflects the following:

3. $\quad$ The impact of JCT investment on Standard of Living (GDPper capita) = j [Computer Hardware Investment (H) + Computer Software Investment (S) + Internal Services Spending (ISS)+ Telecommunication Investment (T) + $\left.\left(H^{*} S\right)+\left(H^{*} I S S\right)+\left(S^{*} I S S\right)+\left(T^{*} H\right)+\left(T^{*} S\right)+\left(T^{*} I S S\right)\right]$

4. $\quad$ The impact of JCT investment on Health $(J S R)=j$ [Computer Hardware Investment $(H)+$ Computer Software Investment $(S)$ + Internal Services Spending (JSS)+Telecommunication Investment (T) $\left.\left(H^{*} S\right)+\left(H^{*} I S S\right)+\left(S^{*} I S S\right)+\left(T^{*} H\right)+\left(T^{*} S\right)+\left(T^{*} I S S\right)\right]$.

\section{Research methodology}

Exploratory research was conducted using archival quantitative data concerning JCT investments and human development over the period 1994 to 2003. The methodology proceeded after the fashion of Kim et al. (2008), and Bankole et al. (2011).

\section{Research context}

Kim et al. (2008) investigated the impact of different facets of ICT investment (hardware, software and internal services spending) on economic development in 51 countries with the largest ICT markets over the period 1993-2001(see Table 2). Kim et al. (2008) grouped the 51 countries into high income, middle income and low income countries respectively, in recognition that national context plays a role in determining how ICT investments might impact economic development. These countries were grouped, based on average GDP per capita over the time period 1993- 2001. The first 17 countries above the two-third percentile of GDP per capita were defined as the High income group; the second 17 countries within the one- third percentile were defined as the Medium income group. The last 17 countries below the one- third percentile were defined as the Low income group countries. 
Table 2. Countries under Assessment (Kim et al., 2008; Bankole et al, 2011)

\begin{tabular}{|c|c|c|c|c|c|c|}
\hline \multirow[t]{2}{*}{$\begin{array}{c}\text { Income } \\
\text { Group }\end{array}$} & \multirow[t]{2}{*}{ List of Countries } & \multicolumn{3}{|c|}{$\begin{array}{l}\text { Avg. Index of HD } \\
\text { Components }\end{array}$} & \multicolumn{2}{|c|}{ Population } \\
\hline & & GDP & Edn & Hlth & Avg Size & $\%$ Urban \\
\hline High & $\begin{array}{l}\text { Japan, Switzerland, } \\
\text { Norway, Denmark, } \\
\text { USA, Sweden, } \\
\text { Germany, Austria, } \\
\text { Singapore, } \\
\text { Netherlands, Belgium, } \\
\text { France, Hong Kong, } \\
\text { Finland, UK, Ireland, } \\
\text { Canada }\end{array}$ & $95 \%$ & $95 \%$ & $89 \%$ & 43 Million & $\begin{array}{l}60 \%- \\
100 \%\end{array}$ \\
\hline Medium & $\begin{array}{l}\text { Australia, Italy, Israel, } \\
\text { New Zealand, Spain, } \\
\text { Taiwan, Greece, } \\
\text { Portugal, South Korea, } \\
\text { Slovenia, Argentina, } \\
\text { Saudi Arabia, Czech } \\
\text { Republic, Mexico, } \\
\text { Hungary, Chile, Brazil }\end{array}$ & $86 \%$ & $90 \%$ & $83 \%$ & 36 Million & $\begin{array}{l}40 \%- \\
92 \%\end{array}$ \\
\hline Low & $\begin{array}{l}\text { Malaysia, Venezuela, } \\
\text { Poland, Slovakia, } \\
\text { South Africa, Turkey, } \\
\text { Egypt, Colombia, } \\
\text { Thailand, Russia, } \\
\text { Romania, Bulgaria, } \\
\text { Philippines, Indonesia, } \\
\text { China, India, Vietnam }\end{array}$ & $74 \%$ & $82 \%$ & $72 \%$ & 200 Million & $\begin{array}{l}26 \%- \\
94 \%\end{array}$ \\
\hline
\end{tabular}

The same set of countries were used in this study, save that data was collected over a different time period (1994 to 2003), and included additional variables not examined by Kim et al. (2008), i.e., telecommunications investments, and the health dimension of human development. It should be noted that the notion of low income countries in this study is relative to the pool of 51 countries with the largest global ICT markets. Hence the countries in this low income grouping should not be confused with the broader perception of low income countries, typically referred to as least developed countries (LDCs). LDCs do not appear among the 51 countries with the largest ICT markets.

\section{Assessment of the suitability of Kim et al. (2008)'s categorization scheme}

Kim et al.'s (2008) categorization scheme is based on average GDP per capita over the period 1993-2001. In order to assess the appropriateness of this categorization scheme for this study, the 51 countries were regrouped based on their human development index (HDI) ranking and averaged GDP per capita (Current US \$) over the period of this study (1994-2003). It was observed that all the countries remained within the same GDP group (except China which moved from the low income to medium income group). It was decided to retain the original Kim et al. (2008) categorization in order to allow for comparison and consistency with previous 
studies (Kim et al., 2008 and Bankole et al, 2011). Next, data envelopment analysis (DEA) was performed to compare the average efficiency score of each group.

Data Envelopment Analysis (Charnes et al., 1978) is a technique for evaluating the relative performance of each decision making unit (DMU) with respect to a given set of DMUs. The DMU is a distinct unit that converts multiple inputs to multiple outputs. A Data Envelopment Analysis (DEA) model can be either input-oriented or outputoriented. An Input-Oriented model focuses on the minimization of the use of the inputs for achieving a given level of the output (Cook \& Seiford, 2009). Under this orientation, a relatively efficient DMU orientation cannot reduce its levels of inputs any further and so has a relative efficiency score of 1 , while relatively inefficient DMUs could have a non-negative relative efficiency score that is less than 1 .

Conversely, an Output-Oriented DEA model is concerned with the maximization of the level of the outputs per given level of inputs. DEA can also be applied under different underlying economic assumptions about the returns to scale (Cook \& Seiford, 2009). For example, an assumption of the constant return-to-scale (CRS) model reflects the situation where the changes in output are in the same proportion as the changes in inputs, while assumptions of the variable returns-to-scale (VRS) model reflects increasing returns to scale.

In this study, an input-oriented VRS model was developed to generate the relative efficiency scores of the 51 countries. The input variables were investments in Hardware, Software, Internal IT Services, and Telecommunications. The output variables covered the three dimensions of HD: standard of living (GDP), health (LER,

ISR), and education (literacy rate (LIR), Education attainment Index [primary school enrollment (PSE), secondary school enrollment (SSE), tertiary school enrollment (TSE)]. The average relative efficiency score for each group of Kim et al (2008)'s scheme were computed (as in Table 3). These results suggest that the average performance of the High group of countries is superior to that of the Medium group which is superior to that of the Low group.

These results of the DEA analysis can be considered as offering additional support to the appropriateness of using Kim et al's (2008) scheme and for comparisons in future studies.

Table 3. Relative Efficiency of Grouped Countries in the sample

\begin{tabular}{|c|c|}
\hline Country Groupings & Avg. Relative Efficiency Score \\
\hline High income countries & 0.88 \\
\hline Medium income countries & 0.79 \\
\hline Low income countries & 0.69 \\
\hline
\end{tabular}

\section{Data collection}

Data on ICT investments and human development (HD) for each of the 51 countries were collected for the period 1994-2003 from four different sources - the UN and 
World Bank (for human development - standard of living [GDP] and health [infant survival rate]), the ITU (for telecommunication investment), and WITSA databases (for IT investment, i.e., hardware, software and internal services spending). The period 1994 to 2003 was chosen, as complete data sets on both ICT investment and human development for the 51 countries were available. This time period was also an era during which IT organizations, particularly in the United States, invested significantly in ICT infrastructure which led to overcapacity of telecommunications networks (Friedman, 2005). This over-investment in ICT infrastructure benefited several developing and emerging economies. For example, it helped India to develop a robust IT-ITES (IT enabled services) outsourcing industry (Friedman, 2005). Currently, India has the reputation of being a premier offshore location.

Table 4 displays a summary of the logarithm of the minimum and maximum values for each ICT component variable in the given sample dataset for each group. The logarithm is reported because, as previously stated, the conceptual model involves a production function framework that has some similarity to the translog production function. The variables are represented as Software (S), Hardware (H), Infant Survival Rate (ISR), GDP (G), Telecommunication (T), and Internal Services Spending (ISS).

Table 4. Range of Log values of Variables

\begin{tabular}{|l|l|l|l|l|l|l|}
\hline \multirow{2}{*}{ Variable } & \multicolumn{2}{|l|}{ High Group } & \multicolumn{2}{c|}{ Medium Group } & \multicolumn{2}{c|}{ Low Group } \\
\cline { 2 - 7 } & Min & Max & Min & Max & Min & Max \\
\hline S & 4.84 & 13.09 & 3.43 & 8.63 & 1.95 & 8.04 \\
\hline ISS & 5.3 & 12.45 & 4.74 & 9.57 & 3.62 & 8.11 \\
\hline H & 5.98 & 12.01 & 4.93 & 9.27 & 4.39 & 10.12 \\
\hline I & 7.44 & 13.09 & 5.02 & 10.34 & 4.80 & 10.68 \\
\hline G & 0.89 & .99 & 0.41 & 0.99 & 0.21 & 0.98 \\
\hline ISR & 6.81 & 6.90 & 6.81 & 6.90 & 6.84 & 6.91 \\
\hline
\end{tabular}

\section{Data analysis procedure - Overview of regression splines}

Multivariate Adaptive Regression Splines (MARS) is a technique developed by Jerome Friedman in the early 1990s to overcome the disadvantages of ordinary regression methods (ORMs). MARS is a method based on modem forms of statistical learning which are important for regression and classification (Weber et al., 2010). While ordinary regression equations attempt to model the linear relationship between independent and dependent variables using a single function, the regression splines approach models the relationships between independent variables and dependent variables as linear and nonlinear. Combinations of piecewise polynomial basis functions (BF) are used that are joined together smoothly at the knots, where a knot specifies the end of one region of data and the beginning of another. MARS uses both simple and complex BFs. Simple BFs involve a single variable and come in pairs of the form $(\mathrm{x}-t)+$ and $(\mathrm{t}$ $-x)+$ where $t$ is the knot, $(\mathrm{x}-t)+=$ if $x>t$, and o otherwise; and $(\mathrm{t}-x)+=(t-$ 
$x$ ) if $x<t$, and $Q$ otherwise (Hastie and Tibshirani 1990). Complex BFs have the form: $h_{k}(\mathrm{x})=\mathrm{IT}_{\mathbf{j}} f_{i j}(x i)$ where $x_{1}, \ldots x_{q}$ are the independent variables, $f_{i j}$ is a spline BF for the $\mathrm{i}^{\text {th }}$ independent variable $x_{i}$ at $\mathrm{j}^{\text {th }}$ knot. The function generated using the MARS approach can be described as follows:

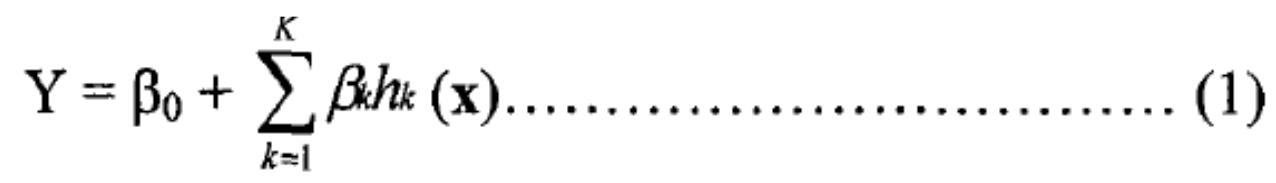

Where $\beta_{0}$ is the coefficient of the constant BF. J3k $(\mathrm{k}=1, \mathrm{~K})$ are the coefficients of the $\mathrm{BFs}$, where $\mathrm{K}$ is the number of basis functions (BF) in the model. The coefficient of each BF (i.e./Jk) is estimated by minimizing the sum of square errors, which is similar to the estimation process of linear regression, but involving local data for the given region. MARS provides the analysis of variance (ANOVA) decomposition, which identifies the relative contributions of each of the independent variables and the interactions between variables, and handles missing values for effective data estimation (Osei-Bryson \& Ko, 2004).

The MARS capability entails the selection of suitable explanatory variables, and the elimination of the least useful explanatory variables, from the selected set, thereby building a model in a two-phase process: first forward and the second backward stepwise algorithms.

The forward MARS algorithm models by minimizing mean square error (MSE) across the model space while looking for combinations of variables and knot locations that could improve the model fit in a forward stepwise approach (Balshi et al., 2009). This algorithm preserves the knot and variable pairs that provide the best model fit, and adjust the response by employing linear functions that are non zero on one side of the knot (Balshi et al., 2009). After a variable is selected in the forward phase approach, the subsequent variables depend on the previous split of the parent basis function (i.e. splitting on one side of the knot). The knots selection is determined by a search procedure. Therefore inclusion of several knots is allowed in the MARS model, as it is assumed that at least one simulated knot will correspond to the observed value of the predictor (Salford Systems, 2001). MARS specifies the location and number of knots needed in both forward and backward stepwise phases. There is no pre-specified number for the set of knot locations because the true function could be smooth, the MARS basis functions (BFs) are therefore used for generalizing the search for knots. The BFs are also used to represent the information contained in one or more variables and to re-express the relationship between predictor variables and target variable (Salford Systems, 2001). Overall, the BFs are set to test every possible knot location and select the model with the best fit. For example, in the backward stepwise algorithm, the set of explanatory variables is reduced according to a residual sum of squares criterion in a reverse stepwise approach, while the optimal model is achieved based on a generalized crossvalidation (GCV) measure of the MSE (Ko \& Osei-Bryson, 2004; Balshi et al., 2009). The GCV measure plays a trade-off role between accuracy and simplicity in the generation of MARS models as that played by the Akaike Information 
Criterion (AIC), Bayes Information Criterion (BIC), and Shwartz Bayes Criterion (SBC) measures play in traditional regression (Osei-Bryson \& Ko, 2004). The GCV is also used to determine the variables to retain or to eliminate, and to establish their order of importance (rank) in the MARS model while ensuring model fit. MARS software such as Salford Systems software can be used in research as a computer assisted approach to regression splines.

\section{Results of regression splines analysis}

The data was analysed using Salford System's MARS software (Version 6.6). Six regression splines models were explored: three where Standard of Living (as measured by GDP) was the dependent variable, for each of high, medium and low income countries, and three where Health (as measured by ISR) was the dependent variable, again for each of high, medium and low income countries respectively. For the forward phase modeling, the maximum numbers of Basis Functions (BFs) parameters were set to 30 , with minimum number of observations between the Knots set to 16, allowing for two-way interactions. Setting the forward phase model to 16 maximum $\mathrm{BFs}$ and 50 observations between knots provides many opportunities for the MARS algorithm to learn during the iteration process.

\section{Impacts of ICT investments on standard of living}

Table 5 presents the 3 separate regression splines models, each describing the impacts of the ICT component variables on Standard of Living (as measured by GDP) for the relevant groups.

These results suggest that there are interactions between the four ICT components that determine their impacts on GDP. For example, an examination of Table 5 indicates that for the High group, 5 of its 9 BFs involve interactions, and for the Medium and Low groups all of the BFs involve interactions. For each group, the relevant BFs suggest that the impact of each ICT component is conditional, depending on both the value of the given ICT component and at least one other ICT component.

In order to demonstrate the conditional impacts of the ICT component variables, a more detailed analysis is needed. The direction of the impacts of two of the ICT component variables: Telecommunications and Software variables are examined. The use of these two variables should not be interpreted to mean that this study is not concerned about the impacts of the other two ICT component variables - Hardware $(\mathrm{H})$ and Internal Services Spending (ISS). Rather, typically at least one of these two variables play a conditioning role on the Direction of Impact of Telecommunications and Software variables. It should be noted that in some cases the conditions under which the given variable may have a positive or negative impact is not presented in the tables, as the main purpose of this analysis is to demonstrate that it is possible for impacts to be in different directions. 
Table 5. Regression Splines Models - Impacts of ICT investments on Standard of Living

\begin{tabular}{|c|c|c|c|}
\hline Group & $\overline{\mathbf{B}} \mathbf{F}$ & Coeff. & Expression \\
\hline \multirow{9}{*}{$\begin{array}{l}\text { High } \\
\text { Adj R2 = } \\
0.394\end{array}$} & BF2 & -0.061 & $\operatorname{Max}\{0,9.08-\log (\mathrm{S})\}$ \\
\hline & $\mathrm{BF} 3$ & -0.198 & $\operatorname{Max}\{0, \log (\mathrm{I})-6.9\}$ \\
\hline & BF5 & -0.146 & $\operatorname{Max}\{0, \log (\mathrm{I})-10.57)\}^{*} \operatorname{Max}\{0, \log (\mathrm{S})-9.08\}$ \\
\hline & BF8 & 0.039 & $\operatorname{Max}\{0,9.96-\log (\mathrm{H})\}$ \\
\hline & BF9 & 0.078 & $\operatorname{Max}\{0, \log (\mathrm{I})-7.39)\}^{*} \operatorname{Max}\{0,9.08-\log (\mathrm{S})\}$ \\
\hline & BF10 & -0.018 & $\operatorname{Max}\{0,7.39-\log (\mathrm{I})\}^{*} \operatorname{Max}\{0,9.08-\log (\mathrm{S})\}$ \\
\hline & BF12 & 0.057 & $\operatorname{Max}\{0, \log (\mathrm{S})-6.92)\}^{*} \operatorname{Max}\{0, \log (\mathrm{I})-6.9\}$ \\
\hline & $\overline{B F 14}$ & 0.047 & $\operatorname{Max}\{0, \log (\mathrm{I})-8.61\}$ \\
\hline & BF18 & -0.815 & $\left.\operatorname{Max}\{0, \log (\mathrm{T})-10.52)\}^{*} \operatorname{Max}\{0,10.57-\log (\mathrm{I})\}\right\}$ \\
\hline \multirow{7}{*}{$\begin{array}{l}\text { Medium } \\
\text { Adj R2 = } \\
0.549\end{array}$} & BF5 & 0.109 & $\operatorname{Max}\{0, \log (\mathrm{I})-7.52)\}^{*} \operatorname{Max}\{0, \log (\mathrm{S})-5.95\}$ \\
\hline & BF9 & -0.546 & $\operatorname{Max}\{0, \log (\mathrm{H})-6.82)\}^{*} \operatorname{Max}\{0,5.95-\log (\mathrm{S})\}$ \\
\hline & $\overline{\text { BF11 }}$ & -0.139 & $\operatorname{Max}\{0, \log (\mathrm{I})-7.6)\}^{*} \operatorname{Max}\{0, \log (\mathrm{T})-8.52\}$ \\
\hline & BF12 & -0.478 & $\operatorname{Max}\{0,7.6-\log (\mathrm{I})\}^{*} \operatorname{Max}\{0, \log (\mathrm{T})-8.52\}$ \\
\hline & $\overline{B F 13}$ & -0.046 & $\operatorname{Max}\{0, \log (\mathrm{I})-4.74)\}^{*} \operatorname{Max}\{0,5.95-\log (\mathrm{S})\}$ \\
\hline & $\overline{\text { BF14 }}$ & -0.174 & $\operatorname{Max}\{0, \log (\mathrm{S})-7.02)\}^{*} \operatorname{Max}\{0,7.94-\log (\mathrm{H})\}$ \\
\hline & BF16 & 0.024 & $\operatorname{Max}\{0, \log (\mathrm{S})-3.43)\}^{*} \operatorname{Max}\{0,7.94-\log (\mathrm{H})\}$ \\
\hline \multirow{7}{*}{$\begin{array}{l}\text { Low } \\
\text { Adj R2 = } \\
0.567\end{array}$} & BF6 & -0.693 & $\operatorname{Max}\{0,6.07-\log (\mathrm{I})\}^{*} \operatorname{Max}\{0, \log (\mathrm{T})-6.14\}$ \\
\hline & BF7 & 0.228 & $\operatorname{Max}\{0, \log (\mathrm{H})-8.15)\}^{*} \operatorname{Max}\{0, \log (\mathrm{S})-5.86\}$ \\
\hline & BF8 & 0.829 & $\operatorname{Max}\{0,8.15-\log (\mathrm{H})\}^{*} \operatorname{Max}\{0, \log (\mathrm{S})-5.86\}$ \\
\hline & BF9 & -0.163 & $\operatorname{Max}\{0, \log (\mathrm{S})-5.61)\}^{*} \operatorname{Max}\{0, \log (\mathrm{T})-6.14\}$ \\
\hline & $\mathrm{BF} 10$ & -0.176 & $\operatorname{Max}\{0,5.61-\log (S)\}^{*} \operatorname{Max}\{0, \log (\mathrm{T})-6.14\}$ \\
\hline & BF11 & 0.049 & $\operatorname{Max}\{0, \log (H)-7.6)\}^{*} \operatorname{Max}\{0, \log (T)-6.14\}$ \\
\hline & BF12 & 0.139 & $\operatorname{Max}\{0,7.6-\log (\mathrm{H})\}^{*} \operatorname{Max}\{0, \log (\mathrm{T})-6.14\}$ \\
\hline
\end{tabular}

For example, considering the impact of the Telecommunications (T) variable for the High group, only $\mathrm{BF} 18$ (i.e. $\operatorname{Max}\{\mathrm{O}, \log (\mathrm{T})-10.52\} * \operatorname{Max}\{\mathrm{O}, 10.57-\log (\mathrm{I})\}$ ) applies, and the relevant knot is $\log (\mathrm{T})=10.52$. The knots are used to specify the relevant intervals, and the relevant Contribution Expression can then be specified for each interval. Since there is only one knot (i.e., $\log (T)=10.52)$ then the relevant intervals are: $\log (\mathrm{T})::: ; 10.52$ and $\log (\mathrm{T})>10.52$, and there are two Contribution Expressions (as in Table 6). Each Direction of Impact Expression is then obtained by taking the first derivative with respect to the log of the given ICT component variable (e.g., $\log (\mathrm{T})$ ) of the corresponding Contribution Expression (as in Table 6). In this example, the Direction of Impact of Telecommunications (T) is either: (a) Q if $\log (\mathrm{T})$ :::; 10.52; (b) $(-0.815 *(10.57-\log (\mathrm{D})$ if $(\log (\mathrm{T})>10.52) \&(\log (\mathrm{I})<10.57)$; and $\mathrm{Q}$ if $(\log (\mathrm{T})>10.52) \&(\log (\mathrm{I})$ 10.57). In other words, this suggests that there could be No impact or a Negative impact, and that the actual impact is determined by the values of $\mathrm{T}$ and $\mathrm{I}$. 
Table 6. Development of Direction of Impact Expressions

\begin{tabular}{|l|l|l|}
\hline $\begin{array}{c}\text { Interval: } \\
\log (\mathbf{T})\end{array}$ & \multicolumn{1}{|c|}{ Contribution Expression } & \multicolumn{1}{c|}{$\begin{array}{c}\text { Direction of Impact } \\
\text { Expression }\end{array}$} \\
\hline$\leq 10.52$ & $-0.815^{*} 0^{*} \operatorname{Max}\{0,10.57-\log (\mathbf{I})\}=0$ & 0 \\
\hline$>10.52$ & $-0.815^{*}(\log (\mathbf{T})-10.52)^{*} \operatorname{Max}\{0,10.57$ & $\begin{array}{l}-0.815^{*} \operatorname{Max}\{0,10.57- \\
\log (\mathbf{I})\}\end{array}$ \\
\hline
\end{tabular}

The data in Tables 7 and 8 are obtained using the basis functions that include the relevant variables (as in Table 5). The results displayed in Table 7 suggest that the impact of Telecommunications (T) varies depending on the given context (i.e., High, Medium, and Low), the value of the Telecommunications variable and the value of at least one other ICT component variable. For example, for the High group if $\log (\mathrm{T})>$ 10.52 then the impact of investments in Telecommunications is Negative if log (I) < 10.57, otherwise it has no impact. Thus for the High group, the direction of impact of Telecommunications investments is dependent on both the amount invested in Telecommunications (T) and the amount invested in Internal Services Spending (ISS). 
Table 7. Impact of Investments in Telecommunication ( $T$ ) on Standard of Living

\begin{tabular}{|c|c|c|c|c|}
\hline \multirow[t]{2}{*}{ Grp } & \multirow[t]{2}{*}{$\log (\mathrm{T})$} & \multirow{2}{*}{$\begin{array}{l}\text { Variable Impact } \\
\text { Expression }\end{array}$} & \multicolumn{2}{|c|}{ Direction of Impact } \\
\hline & & & $\begin{array}{c}\text { Rate of Impact } \\
\text { Expression }\end{array}$ & Assessment \\
\hline \multirow[t]{2}{*}{ High } & $\leq 10.52$ & None & None & None \\
\hline & $>10.52$ & $\begin{array}{l}\left.-0.815^{*}(\log (\mathrm{T})-10.52)\right) \\
* \operatorname{Max}\{0,10.57-\log (\mathrm{I})\}\end{array}$ & $\begin{array}{l}-0.815^{*} \operatorname{Max}\{0,10.57 \\
-\log (I)\}\end{array}$ & $\begin{array}{l}\text { Negative if } \log (\mathrm{I}) \\
<10.57 \\
\text { None } \\
>10.57\end{array}$ \\
\hline \multirow[t]{2}{*}{ Med } & $\leq 8.52$ & None & None & None \\
\hline & $>8.52$ & $\begin{array}{l}-0.139 * \operatorname{Max}\{0, \log (\mathrm{I})- \\
7.6)\} \\
*(\log (\mathrm{T})-8.52) \\
-0.478 * \operatorname{Max}\{0,7.6- \\
\log (\mathrm{I})\} \\
*(\log (\mathrm{T})-8.52)\end{array}$ & $\begin{array}{l}-0.139 * \operatorname{Max}\{0, \log (\mathrm{I}) \\
-7.6)\} \\
-0.478 * \operatorname{Max}\{0,7.6- \\
\log (\mathrm{I})\}\end{array}$ & Negative \\
\hline \multirow[t]{2}{*}{ Low } & $\leq 6.14$ & None & None & None \\
\hline & $>6.14$ & $\begin{array}{l}-0.693 * \operatorname{Max}\{0,6.07- \\
\log (\mathrm{I})\} \\
*(\log (\mathrm{T})-6.14) \\
-0.163 * \operatorname{Max}\{0, \log (\mathrm{S})- \\
5.61)\} \\
*(\log (\mathrm{T})-6.14) \\
-0.163 * \operatorname{Max}\{0, \log (\mathrm{S})- \\
5.61)\} \\
*(\log (\mathrm{T})-6.14) \\
-0.176^{*} \operatorname{Max}\{0,5.61- \\
\log (\mathrm{S})\} \\
*(\log (\mathrm{T})-6.14) \\
+0.049^{*} \operatorname{Max}\{0, \log (\mathrm{H}) \\
-7.6)\} \\
*(\log (\mathrm{T})-6.14) \\
+0.139 * \operatorname{Max}\{0,7.6- \\
\log (\mathrm{H})\} \\
*(\log (\mathrm{T})-6.14)\end{array}$ & $\begin{array}{l}-0.693 * \operatorname{Max}\{0,6.07- \\
\log (\mathrm{I})\} \\
-0.163^{*} \operatorname{Max}\{0, \log (\mathrm{S}) \\
-5.61)\} \\
-0.163 * \operatorname{Max}\{0, \log (\mathrm{S}) \\
-5.61)\} \\
-0.176 * \operatorname{Max}\{0,5.61- \\
\log (\mathrm{S})\} \\
+0.049 * \operatorname{Max}\{0, \\
\log (\mathrm{H})-7.6)\} \\
+0.139 * \operatorname{Max}\{0,7.6- \\
\log (\mathrm{H})\}\end{array}$ & $\begin{array}{l}\text { Conditional: } \\
\text { Could be Positive, } \\
\text { Negative or None } \\
\text { depending on } \\
\text { values of } H, I, S\end{array}$ \\
\hline
\end{tabular}

These results suggest that, depending on the context and condition of ICT investments, the impact of investment in Telecommunications could be Positive, Negative, or Non-existent. To some extent the suggestion of conditional impact may help to explain the seemingly contradictory results of previous studies (e.g., WoldeRufael, 2007; Beil et al., 2005) on the impact of Telecommunication investments on GDP.

The reader may observe that the condition under which Telecommunications (T) has an impact on GDP for the High group is different from that for the Medium or Low group. This suggests that the relative impacts of ICT components vary according to the context (i.e., High, Medium, or Low group). In Table 8, only results for the High and Low groups are reported for illustrative purposes. These results suggest that complex conditional impacts hold for the relationship between investments in Software (S) and Standard of Living (as measured by GDP). 
Table 8. Impact of Investments in Software (S) on Standard of Living

\begin{tabular}{|c|c|c|c|c|}
\hline \multirow[t]{2}{*}{ GRP } & \multirow[t]{2}{*}{$\log (\mathbf{S})$} & \multirow{2}{*}{$\begin{array}{l}\text { Variable Impact } \\
\text { Expression }\end{array}$} & \multicolumn{2}{|c|}{ Direction of Impact } \\
\hline & & & $\begin{array}{l}\text { Rate of Impact } \\
\text { Expression }\end{array}$ & Assessment \\
\hline \multirow[t]{3}{*}{ High } & $<6.92$ & $\begin{array}{l}-0.061 *(9.08-\log (\mathrm{S})) \\
+0.078^{*} \operatorname{Max}\{0, \log (\mathrm{I}) \\
-7.39)\} \\
*(9.08-\log (\mathrm{S})) \\
-0.018^{*} \operatorname{Max}\{0,7.39- \\
\log (\mathrm{I})\} \\
*(9.08-\log (\mathrm{S}))\end{array}$ & $\begin{array}{l}0.061 \\
-0.078^{*} \operatorname{Max}\{0, \log (\mathrm{I}) \\
-7.39)\} \\
+0.018^{*} \operatorname{Max}\{0,7.39 \\
\log (\mathrm{I})\}\end{array}$ & $\begin{array}{l}\text { Positive if } \\
\log (I)<7.39- \\
(0.061 / 0.078)=8.17 \\
\text { Negative otherwise }\end{array}$ \\
\hline & $\begin{array}{l}{[6.92,} \\
9.08)\end{array}$ & $\begin{array}{l}-0.061 *(9.08-\log (\mathrm{S})) \\
+0.078 * \operatorname{Max}\{0, \log (\mathrm{I}) \\
-7.39)\} \\
*(9.08-\log (\mathrm{S})) \\
-0.018 * \operatorname{Max}\{0,7.39- \\
\log (\mathrm{I})\} \\
*(9.08-\log (\mathrm{S})) \\
+0.057 *(\log (\mathrm{S})-6.92) \\
* \operatorname{Max}\{0, \log (\mathrm{I})- \\
6.92\}\end{array}$ & $\begin{array}{l}0.061 \\
-0.078 * \operatorname{Max}\{0, \log (\mathrm{I}) \\
-7.39)\} \\
+0.018 * \operatorname{Max}\{0,7.39- \\
\log (\mathrm{I})\} \\
+0.057 * \operatorname{Max}\{0, \\
\log (\mathrm{I})-6.9\}\end{array}$ & $\begin{array}{l}\text { Positive if } \\
\log (I)<7.63 \\
\text { Negative otherwise }\end{array}$ \\
\hline & $\geq 9.08$ & $\begin{array}{l}-0.146^{*} \operatorname{Max}\{0, \log (\mathrm{I})- \\
10.57)\} \\
*(\log (\mathrm{S})-9.08) \\
+0.057 *(\log (\mathrm{S})-6.92) \\
* \operatorname{Max}\{0, \log (\mathrm{I})-6.9\}\end{array}$ & $\begin{array}{l}-0.146 * \operatorname{Max}\{0, \log (\mathrm{I}) \\
-10.57)\} \\
+0.057 * \operatorname{Max}\{0 \\
\log (\mathrm{I})-6.9\}\end{array}$ & $\begin{array}{l}\text { Positive if } \\
\log (I) \in(6.9,12.92) \\
\text { Negative if } \log (I) \\
>12.92 \\
\text { NONE if } \log (I)< \\
6.9\end{array}$ \\
\hline \multirow[t]{3}{*}{ Low } & $<5.61$ & $\begin{array}{l}-0.176^{*}(5.61-\log (\mathrm{S})) \\
* \operatorname{Max}\{0, \log (\mathrm{T})- \\
6.14\}\end{array}$ & $\begin{array}{l}0.176^{*} \operatorname{Max}\{0, \log (T)- \\
6.14\}\end{array}$ & $\begin{array}{l}\text { Positive if } \log (T)> \\
6.14 \\
\text { None } \quad \text { otherwise }\end{array}$ \\
\hline & $\begin{array}{l}5.61 \\
5.86]\end{array}$ & $\begin{array}{l}-0.163 *(\log (S)-5.61)) \\
* \operatorname{Max}\{0, \log (T)-6.14\}\end{array}$ & $\begin{array}{l}-0.163 * \operatorname{Max}\{0, \log (T) \\
-6.14\}\end{array}$ & $\begin{array}{ll}\text { Negative } & \text { if } \log (T)> \\
6.14 & \\
\text { None } & \text { otherwise }\end{array}$ \\
\hline & $>5.86$ & $\begin{array}{l}0.228 * \operatorname{Max}\{0, \log (\mathrm{H})- \\
8.15)\} \\
*(\log (\mathrm{S})-5.86) \\
+0.829 * \operatorname{Max}\{0,8.15- \\
\log (\mathrm{H})\} \\
*(\log (\mathrm{S})-5.86\}) \\
-0.163 *(\log (\mathrm{S})-5.61)) \\
* \operatorname{Max}\{0, \log (\mathrm{T})-6.14\}\end{array}$ & $\begin{array}{l}0.228^{*} \operatorname{Max}\{0, \log (\mathrm{H}) \\
-8.15)\} \\
+0.829 * \operatorname{Max}\{0,8.15- \\
\log (\mathrm{H})\} \\
-0.163^{*} \operatorname{Max}\{0, \log (\mathrm{T}) \\
-6.14\}\end{array}$ & $\begin{array}{l}\text { Positive if } \log (T) \leq \\
6.14 \\
\text { Otherwise could be } \\
\text { Positive, Negative } \\
\text { depending on } \\
\text { relationship between } \\
H \& T \text { values }\end{array}$ \\
\hline
\end{tabular}

\section{Impacts of ICT on standard of health}

Table 9 presents three separate models, each describing the impacts of the ICT component variables on Health (as measured by JSR) for the relevant groups. The results in Tables 10 and 11 are obtained from Table 9 in a manner similar to that used to obtain the results in Tables 7 and 8 from the results displayed in Table 5 . 
Table 9. Regression Splines Models - Impacts of ICT investments on Health

(ISR)

\begin{tabular}{|c|c|c|}
\hline Group & BF & Expression incl Coefficient \\
\hline \multirow{12}{*}{$\begin{array}{l}\text { High } \\
\text { Adj R }^{2}= \\
\underline{0.701}\end{array}$} & BF1 & $-0.035^{*} \operatorname{Max}\{0, \log (\mathrm{I})-7.79\}$ \\
\hline & BF2 & $0.148 * \operatorname{Max}\{0,7.79-\log (\mathrm{I})\}$ \\
\hline & $\mathrm{BF} 3$ & $-0.019 * \operatorname{Max}\{0, \log (\mathrm{S})-9.54\}$ \\
\hline & BF4 & $-0.020 * \operatorname{Max}\{0,9.54-\log (\mathrm{S})\}$ \\
\hline & BF5 & $\left.0.010^{*} \operatorname{Max}\{0, \log (\mathrm{I})-7.25)\right\}^{*} \operatorname{Max}\{0,9.54-\log (\mathrm{S})\}$ \\
\hline & BF6 & $-0.057^{*} \operatorname{Max}\{0,7.25-\log (\mathrm{I})\} * \operatorname{Max}\{0,9.54-\log (\mathrm{S})\}$ \\
\hline & BF7 & $\left.-0.388^{*} \operatorname{Max}\{0, \log (\mathrm{S})-6.42)\right\}^{*} \operatorname{Max}\{0,7.79-\log (\mathrm{I})\}$ \\
\hline & BF8 & $0.031 * \operatorname{Max}\{0,6.42-\log (\mathrm{S})\}^{*} \operatorname{Max}\{0,7.79-\log (\mathrm{I})\}$ \\
\hline & BF9 & $0.037 * \operatorname{Max}\{0, \log (T)-9.54)\} * \operatorname{Max}\{0, \log (\mathrm{I})-7.79\}$ \\
\hline & BF10 & $0.030 * \operatorname{Max}\{0,9.54-\log (T)\}^{*} \operatorname{Max}\{0, \log (\mathrm{I})-7.79\}$ \\
\hline & BF11 & $\left.-0.033^{*} \operatorname{Max}\{0, \log (\mathrm{T})-10.11)\right\}^{*} \operatorname{Max}\{0, \log (\mathrm{I})-7.79\}$ \\
\hline & $\mathrm{BF} 13$ & $\left.0.039^{*} \operatorname{Max}\{0, \log (\mathrm{H})-7.04)\right\} * \operatorname{Max}\{0,7.79-\log (\mathrm{I})\}$ \\
\hline \multirow{8}{*}{$\begin{array}{l}\text { Medium } \\
\text { Adj R }^{2}= \\
\underline{0.476}\end{array}$} & $\mathrm{BF} 4$ & $-0.138 * \operatorname{Max}\{0, \log (\mathrm{H})-7.94\}$ \\
\hline & BF6 & $0.033^{*} \operatorname{Max}\{(0, \log (\mathrm{H})-7.41)\}^{*} \operatorname{Max}\{0, \log (\mathrm{S})-4.91\}$ \\
\hline & BF7 & $0.022^{*} \operatorname{Max}\left\{(0,7.41-\log (H)\}^{*} \operatorname{Max}\{0, \log (S)-4.91\}\right.$ \\
\hline & BF8 & $0.018^{*} \operatorname{Max}\{(0, \log (T)-8.29)\}^{*} \operatorname{Max}\{0, \log (\mathrm{I})-4.74\}$ \\
\hline & BF10 & $-0.017 * \operatorname{Max}\{0, \log (S)-4.82)\} * \operatorname{Max}\{0, \log (\mathrm{I})-4.74\}$ \\
\hline & BF12 & $-0.036^{*} \operatorname{Max}\{0, \log (T)-8.2\}$ \\
\hline & BF15 & $-0.101^{*} \operatorname{Max}\left\{(0,7.11-\log (\mathrm{H})\}^{*} \operatorname{Max}\{(0, \log (\mathrm{T})-8.2)\}\right.$ \\
\hline & BF16 & $0.008 * \operatorname{Max}\{(0, \log (\mathrm{H})-4.93)\}^{*} \operatorname{Max}\{0, \log (\mathrm{I})-4.74\}$ \\
\hline \multirow{9}{*}{$\begin{array}{l}\text { Low } \\
\text { Adj }^{2} \\
0.509 \\
\end{array}$} & $\mathrm{BF} 2$ & $-0.053^{*} \operatorname{Max}\{0,4.89-\log (\mathrm{H})\}$ \\
\hline & BF3 & $-0.010 * \operatorname{Max}\{(0, \log (\mathrm{S})-5.51)\}^{*} \operatorname{Max}\{0, \log (\mathrm{H})-4.89\}$ \\
\hline & BF4 & $0.010^{*} \operatorname{Max}\{0,5.51-\log (\mathrm{S})\}^{*} \operatorname{Max}\{0, \log (\mathrm{H})-4.89\}$ \\
\hline & $\mathrm{BF} 7$ & $0.007 * \operatorname{Max}\{0, \log (\mathrm{S})-3.96\}$ \\
\hline & BF8 & $0.013 * \operatorname{Max}\{0,3.96-\log (\mathrm{S})\}$ \\
\hline & BF9 & $0.032 * \operatorname{Max}\{0, \log (\mathrm{T})-9.04\}$ \\
\hline & BF11 & $-0.063 * \operatorname{Max}\{(0, \log (\mathrm{H})-7.33)\} * \operatorname{Max}\{0,9.04-\log (\mathrm{T})\}$ \\
\hline & BF13 & $0.017 * \operatorname{Max}\{(0, \log (\mathrm{I})-6.68)\}$ \\
\hline & BF15 & $0.035^{*} \operatorname{Max}\{(0, \log (\mathrm{S})-6.22)\}$ \\
\hline
\end{tabular}

Results in Table 10 suggest that complex conditional impacts hold for the relationship between investments in Telecommunications (T) and Health (as measured by JSR).

The reader may observe that the condition under which Telecommunications $(T)$ has a positive impact on JSR for the High group is different from the condition for the Low group. This suggests that the relative impacts of the ICT components depend on the context. A comparison with results displayed in Table 7 suggests that the conditions under which Telecommunications (T) has a positive impact on GDP are different from those under which Telecommunications (T) has a positive impact on JSR. 
Table 10. Impact of Investments in Telecommunication (T) on Health (ISR)

\begin{tabular}{|c|c|c|c|c|}
\hline \multirow[t]{2}{*}{ Grp } & \multirow[t]{2}{*}{$\log (T)$} & \multirow{2}{*}{$\begin{array}{l}\text { Variable Impact } \\
\text { Expression }\end{array}$} & \multicolumn{2}{|c|}{ Direction of Impact } \\
\hline & & & $\begin{array}{l}\text { Rate of Impact } \\
\text { Expression }\end{array}$ & Assessment \\
\hline \multirow[t]{3}{*}{ High } & $<9.54$ & $\begin{array}{l}0.030 *(9.54-\log (\mathrm{T})) \\
* \operatorname{Max}\{0, \log (\mathrm{I})- \\
7.79\}\end{array}$ & $\begin{array}{l}-0.030 * \operatorname{Max}\{0, \log (\mathrm{I}) \\
-7.79\}\end{array}$ & $\begin{array}{l}\text { Negative if } \\
\log (I)>7.79 \\
\text { None otherwise }\end{array}$ \\
\hline & $\begin{array}{l}(9.54 \\
10.11)\end{array}$ & $\begin{array}{l}0.037 *(\log (\mathrm{T})-9.54)) \\
* \operatorname{Max}\{0, \log (\mathrm{I})- \\
7.79\}\end{array}$ & $\begin{array}{l}0.037 * \operatorname{Max}\{0, \log (\mathrm{I})- \\
7.79\}\end{array}$ & $\begin{array}{l}\text { Positive if } \\
\log (I)>7.79 \\
\text { None otherwise }\end{array}$ \\
\hline & $>10.11$ & $\begin{array}{l}0.037 *(\log (\mathrm{T})-9.54)) \\
* \operatorname{Max}\{0, \log (\mathrm{I})- \\
7.79\} \\
-0.033 *(\log (\mathrm{T})- \\
10.11)) \\
* \operatorname{Max}\{0, \log (\mathrm{I})- \\
7.79\}\end{array}$ & $\begin{array}{l}0.037^{*} \operatorname{Max}\{0, \log (\mathrm{I})- \\
7.79\} \\
-0.033 * \operatorname{Max}\{0, \log (\mathrm{I}) \\
-7.79\}\end{array}$ & $\begin{array}{l}\text { Positive if } \\
\log (I)>7.79 \\
\text { None otherwise }\end{array}$ \\
\hline \multirow[t]{3}{*}{ Med } & $\leq 8.20$ & None & None & None \\
\hline & $\begin{array}{l}(8.20, \\
8.29]\end{array}$ & $\begin{array}{l}-0.036^{*}(\log (\mathrm{T})-8.2) \\
-0.101^{*} \operatorname{Max}\{(0,7.11- \\
\log (\mathrm{H})\}^{*}(\log (\mathrm{T})- \\
8.2))\end{array}$ & $\begin{array}{l}-0.036 \\
-0.101 * \operatorname{Max}\{(0,7.11- \\
\log (\mathrm{H})\}\end{array}$ & Negative \\
\hline & $>8.29$ & $\begin{array}{l}0.018 *(\log (\mathrm{T})-8.29)) \\
* \operatorname{Max}\{0, \log (\mathrm{I})- \\
4.74\} \\
-0.036 *(\log (\mathrm{T})-8.2) \\
-0.101 * \operatorname{Max}\{(0,7.11- \\
\log (\mathrm{H})\} \\
*(\log (\mathrm{T})-8.2))\end{array}$ & $\begin{array}{l}0.018^{*}(\operatorname{Max}\{0, \log (\mathrm{I})- \\
4.74\} \\
-0.036 \\
-0.101 * \operatorname{Max}\{(0,7.11- \\
\log (\mathrm{H})\}\end{array}$ & $\begin{array}{l}\text { Positive if } \\
\log (I)>6.74 \& \\
\log (H)>7.11 \\
\text { Negative if } \\
\log (I)<4.74 \text { or } \\
\log (H)<7.11 \\
\text { Varies otherwise }\end{array}$ \\
\hline \multirow[t]{2}{*}{ Low } & $<9.04$ & $\begin{array}{l}-0.063 * \operatorname{Max}\{(0 \\
\log (\mathrm{H})-7.33)\} \\
*(9.04-\log (\mathrm{T}))\end{array}$ & $\begin{array}{l}0.063^{*} \operatorname{Max}\{(0, \log (\mathrm{H}) \\
-7.33)\}\end{array}$ & $\begin{array}{l}\text { Positive if } \\
\log (H)>7.33 \\
\text { None otherwise }\end{array}$ \\
\hline & $>9.04$ & $0.032 *(\log (\mathrm{T})-9.04))$ & 0.032 & Positive \\
\hline
\end{tabular}

Table 11 only reports results for the High and Low groups for illustrative purposes. These results suggest that complex conditional impacts hold for the relationships between investments in Software (S) and Health (as measured by JSR). The reader may observe that the condition under which Software (S) has an impact on JSR for the High group is different from that for the Low group. This suggests that the relative impacts of the ICT components depend on the context. A comparison of these results with those displayed in Table 8, suggests that the conditions under which Software (S) has a positive impact on GDP are different from those under which Software (S) has a positive impact on JSR. (Table 11) 
Table 11. Impact of Investments in Software (S) on Health (ISR)

\begin{tabular}{|c|c|c|c|c|}
\hline \multirow[t]{2}{*}{ Grp } & \multirow[t]{2}{*}{$\log (\mathbf{S})$} & \multirow{2}{*}{$\begin{array}{l}\text { Variable Impact } \\
\text { Expression }\end{array}$} & \multicolumn{2}{|c|}{ Direction of Impact } \\
\hline & & & $\begin{array}{l}\text { Rate of Impact } \\
\text { Expression }\end{array}$ & Assessment \\
\hline \multirow[t]{3}{*}{ High } & $<6.42$ & $\begin{array}{l}-0.020 * \operatorname{Max}\{0,9.54- \\
\log (\mathrm{S})\} \\
+0.010 * \operatorname{Max}\{0, \log (\mathrm{I})- \\
7.25)\} \\
* \operatorname{Max}\{0,9.54- \\
\log (\mathrm{S})\} \\
-0.057 * \operatorname{Max}\{0,7.25- \\
\log (\mathrm{I})\} \\
*(9.54-\log (\mathrm{S}))) \\
+0.031 * \operatorname{Max}\{0,6.42- \\
\log (\mathrm{S})\} \\
* \operatorname{Max}\{0,7.79-\log (\mathrm{I})\}\end{array}$ & $\begin{array}{l}0.020 \\
-0.010^{*} \operatorname{Max}\{0, \log (\mathrm{I})- \\
7.25)\} \\
+.057 * \operatorname{Max}\{0,7.25- \\
\log (\mathrm{I})\} \\
-0.031 * \operatorname{Max}\{0,7.79- \\
\log (\mathrm{I})\}\end{array}$ & $\begin{array}{l}\text { Positive if } \\
\log (I) \in(7.25,9.25) \\
\text { Negative if } \log (I)> \\
9.25 \\
\text { Otherwise depending } \\
\text { on value of } \log (I)\end{array}$ \\
\hline & $\begin{array}{l}(6.42, \\
9.54)\end{array}$ & $\begin{array}{l}-0.020^{*}(9.54- \\
\log (\mathrm{S})) \\
+0.010^{*} \operatorname{Max}\{0, \log (\mathrm{I})- \\
7.25)\} \\
*(9.54-\log (\mathrm{S})) \\
-0.057 * \operatorname{Max}\{0,7.25- \\
\log (\mathrm{I})\} \\
*(9.54-\log (\mathrm{S}))) \\
\left.-0.388^{*}(\log (\mathrm{S})-6.42)\right) \\
* \operatorname{Max}\{0,7.79-\log (\mathrm{I})\}\end{array}$ & $\begin{array}{l}0.020 \\
-0.010^{*} \operatorname{Max}\{0, \log (\mathrm{I})- \\
7.25)\} \\
+.057 * \operatorname{Max}\{0,7.25- \\
\log (\mathrm{I})\} \\
-0.388 * \operatorname{Max}\{0,7.79- \\
\log (\mathrm{I})\}\end{array}$ & $\begin{array}{l}\text { Positive if } \\
\log (I) \in(7.25,9.25) \\
\text { Negative if } \log (I)> \\
9.25 \\
\text { Otherwise depending } \\
\text { on value of } \log (I)\end{array}$ \\
\hline & $>9.54$ & $\begin{array}{l}-0.019 *(\log (\mathrm{S})-9.54) \\
-0.388 *(\log (\mathrm{S})-6.42)) \\
* \operatorname{Max}\{0,7.79-\log (\mathrm{I})\}\end{array}$ & $\begin{array}{l}-0.019 \\
-0.388 * \operatorname{Max}\{0,7.79- \\
\log (\mathrm{I})\}\end{array}$ & Negative \\
\hline \multirow[t]{4}{*}{ Low } & $<3.96$ & $+0.013^{*}(3.96-\log (\mathrm{S}))$ & -0.013 & Negative \\
\hline & $\begin{array}{l}(3.96, \\
5.51)\end{array}$ & $+0.007 *(\log (S)-3.96)$ & 0.007 & Positive \\
\hline & $\begin{array}{l}(5.51 \\
6.22)\end{array}$ & $\begin{array}{l}-0.010 *(\log (\mathrm{S})-5.51)) \\
* \operatorname{Max}\{0, \log (\mathrm{H})- \\
4.89\} \\
+0.007 *(\log (\mathrm{S})-3.96)\end{array}$ & $\begin{array}{l}-0.010 * \operatorname{Max}\{0, \log (\mathrm{H}) \\
-4.89\} \\
+0.007\end{array}$ & $\begin{array}{l}\text { Positive if } \\
\log (\mathrm{H})<4.89+ \\
(0.007 / 0.010) \\
\text { Negative otherwise }\end{array}$ \\
\hline & $>6.22$ & $\begin{array}{l}-0.010 *(\log (\mathrm{S})-5.51)) \\
* \operatorname{Max}\{0, \log (\mathrm{H})- \\
4.89\} \\
+0.007 *(\log (\mathrm{S})-3.96) \\
+0.035 *(\log (\mathrm{S})- \\
6.22))\end{array}$ & $\begin{array}{l}-0.010 * \operatorname{Max}\{0, \log (\mathrm{H}) \\
-4.89\} \\
+0.007 \\
+0.035\end{array}$ & $\begin{array}{l}\text { Positive if } \\
\log (\mathrm{H})<4.89+ \\
(0.042 / 0.010) \\
\text { Negative otherwise }\end{array}$ \\
\hline
\end{tabular}

\section{Further comparison of contexts and dimensions}

Many predictive modeling techniques (e.g., regression, regression splines, decision tree induction) provide the means for determining the order of importance of the variables in the generated predictive model. This is represented in the form of a variable importance vector (Tables 12 and 13) where the most important variable in the model is assigned a relative score of $100 \%$, and each variable that was not established to be a predictor is assigned a score of $\mathrm{o} \%$.

Table 12 displays for each group (i.e., High, Medium, or Low), the relative importance of each ICT component variable as a predictor of Standard of Living (as measured by 
GDP). Table 13 provides similar information but for Health as the independent variable. An examination of the results in this pair of tables again suggests that the relative impacts of the four ICT components depend on the context (i.e., High, Medium, or Low group). For example with regards to the predictors of Standard of Living, for the High group, Software is the most important predictor, while for the Low group, Telecommunications is the most important predictor

Table 12. Impact of ICT investments on Standard of Living: Relative Importance of Variables

\begin{tabular}{|l|c|c|c|}
\hline & High Group & Medium Group & Low Group \\
\hline Software (S) & $\mathbf{1 0 0 . 0 0 0}$ & 71.180 & 89.459 \\
\hline Internal Services (ISS) & 68.443 & $\mathbf{1 0 0 . 0 0 0}$ & 27.162 \\
\hline Hardware (H) & 34.254 & 45.998 & 78.847 \\
\hline Telecommunication (T) & 27.134 & 83.960 & $\mathbf{1 0 0 . 0 0 0}$ \\
\hline
\end{tabular}

These results suggest again that the relative impacts of the four ICT components depend on the HD dimension (i.e., Standard of Living, or Health). For the High group, if the focus is on Standard of Living, then Software (S) is the most important predictor (as in Table 12) but if the focus is on Health (as measured by ISR), then Internal Services Spending (ISS) is the most important predictor (as in Table 13).

Table 13. Impact of ICT investments on Health: Relative Importance of Variables

\begin{tabular}{|l|c|c|c|}
\hline & High Group & Medium Group & Low Group \\
\hline Software (S) & 85.689 & $\mathbf{1 0 0 . 0 0 0}$ & 71.895 \\
\hline Internal Services (ISS) & $\mathbf{1 0 0 . 0 0 0}$ & 93.049 & 42.242 \\
\hline Hardware (H) & 29.177 & 96.016 & $\mathbf{1 0 0 . 0 0 0}$ \\
\hline Telecommunication (T) & 57.501 & 57.443 & 72.033 \\
\hline
\end{tabular}

It is interesting to observe that for the low income group, it is investments in basic hardware and telecommunications infrastructure that are most important for human development, whereas for higher income countries, it is the added value components of software and internal services. This is commensurate with the developmental status of the countries, where basic infrastructure is a necessary precursor to value-added services.

\section{Discussion and implications}

The findings of this study provide a better explanation as to the impacts of ICT investment on human development than has hitherto been provided. Most previous studies have examined the impact of ICT investments on economic development, using single measures for each of ICT investments and development. Only a few studies have looked at disaggregating the ICT investments into component parts (Kim et al., 2008, Bankole et al., 2011). This study builds on the two aforementioned prior studies by looking at investments in the ICT components of hardware, software, telecommunications and internal services respectively. Recognising the limitations of conceptualizing development from an economic perspective only, this study draws from the notion of human development as defined by UNDP (2003) to look at two dimensions of development - standard of living and health respectively. Furthermore to 
take in to account the effect of varying context, the countries in the sample are classified as high, medium and low income, depending on their relative GDP per capita over the time period of the study. This is akin to the studies carried out by Kim et al. (2008) and Bankole et al. (2011), but this study goes further by exploring the complex and conditional impacts of ICT investments on human development in these different contexts using the novel technique of regression splines.

The findings reveal that simplistic assumptions about a positive linear relationship between ICT investments and development do not hold. The impact of ICT investments on dimensions of development may not necessarily be positive - they may in fact be negative or absent altogether under certain conditions. This explains the seemingly contradictory results of previous studies (Wolde-Rufael, 2007; Beil et al., 2005) on the impact of ICT investments on development. The variation in impacts is explained mainly by the interaction effect of ICT investment components. For example, the results show that in low income countries, the impact of software investments on standard of living will be positive below a certain threshold, as long as telecommunications investments exceed a certain threshold. This finding confirms that the different components of ICT do not work in isolation, but require optimal integration to have an impact.

In addition, the impacts are different between high, medium and low income countries. Telecommunications investments in high income countries, for example, have either no impact or a negative impact on standard of living depending on the level of internal services spending. The reason may be that high income countries already have an established base of telecommunications infrastructure, and over- investment may lead to a drain on the economy with no corresponding payback. Adequate spending on internal services to utilize new telecommunications capacity may provide some payback, hence nullifying the negative effect, but not necessarily having a positive effect. In contrast, for low income countries, above a certain threshold, telecommunications investments have a positive impact on standard of living, provided there are appropriate levels of hardware, software, and internal services spending.

Differences are also apparent between the impacts of ICT investments on standard of living and health. For example, in high income countries, the impact of telecommunications investments on standard of living is either negative or has no impact, depending on internal services spending. In contrast, the impact of telecommunications investment on health is positive above a certain threshold of telecommunications and internal services spending.

The relative importance of ICT investments vary by context. For example, software investments are the most important ICT component in high income countries, when considering the impact on standard of living (GDP). This may be because high income countries already have a strong base in terms of telecommunications, internal services spending and computer hardware. The high income countries require software investment for process improvements (e.g., huge spending on enterprise systems). Software investments are also required in high income countries to create a competitive advantage since software is a knowledge embedded product (Kim et al., 
2008). The results show the importance of internal services spending to maximize the effect of software on standard of living.

In the case of medium income countries, internal services spending is the most important contributor to standard of living. IT skills (human capital) are a key concern for medium income countries for business and market development (Samoilenko \& Ngwenyama, 2011). Countries in this category may have to contend with problems such as skills flight, as IT professionals are attracted by better salaries and working conditions in the high income countries.

In low income countries, telecommunications investment is the most important contributor to standard of living, and hardware investments the most important for health. In these countries, there is a focus on establishing a necessary base of installed infrastructure as a pre-requisite to investing in value-added software and internal services. This explains the importance of telecommunications and hardware to low income countries. In addition, the spillover investments in telecommunications have enabled countries like India (country in low income group of this study) to develop a robust IT-ITES (IT enabled services) outsourcing industry (Friedman, 2005). India is leading in the sourcing market, with countries such as China, Malaysia and Mexico also opening IT-ITES centers. This occurrence has helped low income countries improve their standard of living. Governments and organizations currently view sourcing as a global activity to achieve business objectives and improve the standard of living of people in low income countries (Friedman, 2005). Improvement in telecommunications infrastructures has facilitated the development of highly skilled pools in low income economies whereby organizations in high income (developed) countries are seeking collaboration with partner firms located in these countries (Rao, Earls \& Sanchez, 2007).

Another notable finding is that the degree of importance of JCT components varies not only between high, medium and low income countries, but also depending on whether standard of living or health is being considered. For example, software investments are the most important for standard of living in high income countries while internal services spending is the most important for health in the same high income countries. The results suggest, among other things, that the impact of investments in the JCT components varies with context and are in many cases conditional and complex. Consequently, the impact of a given component is affected not only by the level of investments in that component but also by at least one other component. This means countries have dissimilar JCT investment utilization (Samoilenko \& Osei-Bryson, 2008). The findings also correspond with Ngwenyama et al., (2006), Kim et al., (2008) and Bankole et al., (2011), whose studies observed that complementary investments are prerequisites for the successful translation of investments in JCT. The analysis makes clear the complexity that is associated with such JCT investment, thereby providing insight into the challenges of JCT investment.

The results offer significant implications for ICT policy makers and decision makers. In considering policies and strategies concerning the levels of ICT investment 
(hardware, telecommunications, software and internal services spending) necessary to impact human development (standard of living and health), decision makers could firstly establish where their country fits with respect to the categories of high, medium or low income. Having established that, decision makers could refer to Tables 12 and 13 to determine which variables to focus attention on. In-depth trade-off analysis could then be carried out based on analyses such as in Tables 5 to 11. The optimal balance between investments in hardware, software, telecommunications and internal services spending, necessary to have maximum impact on standard of living and health could then be determined.

As an illustrative example, it might be that a decision-maker in a /ow income country would like to formulate policy on ICT investments to maximize impact on health. Table 13 shows that hardware investments should be a key focus in this instance, followed by telecommunications and software. Analyses such as in Tables 9 to 11 could be conducted. These analyses show the conditions necessary for telecommunications and software to have a positive impact on health. From Table 10, it can be garnered that in the case of telecommunications investment, below a certain threshold, for there to be a positive impact on health, a certain level of hardware investment is also necessary. Iftelecommunications investment is above the threshold it will have a positive impact on health, independent of the other ICT components.

The decision maker would have to make a determination as to the monetary values implied by the specific thresholds for telecommunications and hardware. Based on budgetary constraints and existing infrastructure, a decision whether to invest in telecommunications below the threshold together with required hardware investment, or whether to invest in telecommunications above the threshold could be made. Sensitivity analysis could also be conducted to ascertain the quantum improvement in health expected from the intended investments. Tables 5 to 11 are presented for illustrative purposes only, hence in order to conduct a comprehensive analysis, decision makers would need to make use of skills in MARS software and regression splines analysis. In the case of formulating policy on ICT investments to improve national health in a low income country, given the importance of hardware investments, an analysis of the conditions under which hardware positively impacts health would have to be conducted.

\section{Limitations and future research}

The main limitation of this study is the issue associated with data availability. The analysis for the study was carried out using a dataset of 51 countries available for the years 1994 to 2003 obtained from World Information Technology Services Alliance (WITSA) and other sources. WITSA is a leading voice of the global IT industry and publishes data about worldwide IT in order to position the role of ICT in global development. Other limitations involved the issue of a lag effect. The time lag between ICT investments and the returns on such investments could have a significant effect on the results obtained. However, the MARS analysis used is sensitive to this situation by offering the potential of detecting any effect of change in ICT investments in order to minimize any lag effect conditions. 
Future research can build on this study by theoretically elaborating on the findings, and offering propositions that explain the complex and conditional impacts. More recent data sets and a larger pool of countries could be used to see whether the results still hold. Future studies could also consider incorporating non-ICT investments that affect human development. To explore the underlying structures and causal mechanisms leading to the negative impact of some ICT investments, techniques such as system dynamics modeling could also be employed.

\section{Summary and conclusion}

This article investigated the impact of four components of ICT investment (hardware, software, telecommunications and internal services spending) on two dimensions of human development (standard of living and health), in three contexts (high, medium and low income countries). Regression splines analysis was employed to determine the conditional impact of such investments. The overall results suggest that the conditions are complex, and that they vary by context. The study reveals the level of importance of each component of ICT to the two dimensions of human development according to the income level of the countries. Software was the most important contributor to standard of living in high income countries, internal services spending in medium income countries and telecommunications in low income countries. This study has contributed knowledge by examining the impact of ICT investments on human development using an archival data set for the period 1994 to 2003. The study shows insight into the application of data mining techniques such as regression splines, to research at the macro analysis level. This is in line with the suggestion by Palvia (2006) that there is need for international research which can provide a guiding framework for future research in this area. Other studies that have investigated ICT investments have not considered the conditional impact on human development. 


\section{REFERENCES}

Bankole, F.O, Shiraz, F., and Brown, I. "Investigating the Impact of ICT Investments on Human Development," Electronic Journal on Information Systems in Developing Countries (48:8), 2011, pp. 1-19.

Balshi, M. S., McGuire, A. D., Duffy, P., Flannigan, M., Walsh, J., and Melillo, J. "Assessing the Response of Area Burned to Changing Climate in Western Boreal North America Using a Multivariate Adaptive Regression Splines (MARS) Approach," Global Change Biology (15: 3), 2009, pp. 578--600.

Beil, R., G. Ford, and Jackson, J. "On the Relationship Between Telecommunications Investment and Economic Growth in the United States," International Economic Journal (19:1), 2005, pp. 3-9.

Berndt, E. and Christensen, L. R.. "The Translog Production Function and the Substitution of Equipment, Structures, and Labour in the US Manufacturing, 1929-1968," Journal of Econometrics (1:8), 1972, pp. 1-114.

Bollou, F. and Ngwenyama, o. "Are ICT Investments Paying Off in Africa? An Analysis of Total Factor Productivity in Six West African Countries from 1995 to 2002," Information Technologyfor Development (20: 9), 2008, pp. 114 .

BMJ "Trends in Socioeconomic Inequalities in Risk of Sudden Infant Death Syndrome, Other Causes of Infant Mortality, and Stillbirth in Scotland: Population Based Study," BMJ (344:e1552), Retrieved 5 December, 2012 from www.bmj/content/344/bmj.e1552, 2012.

Chames, A., Cooper, W. W., and Rhodes, E. "Measuring the Efficiency of Decision Making Units," European Journal of Operational Research (2:6), 1978, pp. 429-444.

Colecchia, A. and Schreyer, P. "ICT Investment and Economic Growth in the1990s: Is the United States a Unique Case? A Comparative Study of Nine OECD Countries," Review of Economic Dynamics (5:2), 2002, pp. 408-442.

Cook, W. D., and Seiford, L. M. "Data Envelopment analysis (DEA) - Thirty years on," European Journal of Operational Research (192:1), 2009, pp. 117.

Daveri, F. 2002. "The New Economy in Europe, ," Oxford Review of Economic Policy (18:3), pp. 345-362, 1992-2001.

Friedman, T.L. "It's a Flat World, After All". New York Times, Retrieved February, 4, 2013, from http://www.nytimes.com/2005/o4/o3/magazine/o3DOMINANCE.html? 2005.

Heisler, E.J "The US Infant Mortality Rate: International Comparisons, Underlying Factors, and Federal Programs," Congressional Research Service No 7-570oo. Retrieved 15 July, 2012 from www.crs.gov, 2011.

ITU: International Telecommunication Union World Information Society Reports, Retrieved September 15, 2010, from http:www.itu.int/ITU-D/ict/index.html, 2007.

Jalava, J. and Pohja, M. "Economic Growth in the New Economy: Evidence from Advanced Economies," Information Economics and Policy (14:2), 2002, pp. 189-210. 
Kim, Y.J., Kang, H., Sanders, G.L. and Lee, S. T. "Differential Effects of IT Investments: Complementarity and the Effect of GDP level," International Journal of Information Management (28:6), 2008, pp. 508-516.

Ko, M. and Osei-Bryson, K.-M. "Using Regression Splines to Assess the Impact of Information Technology Investments on Productivity in the Health Care Industry," Information Systems Journal (14:1), 2004, pp. 43-63.

Kuppusanmy, M. and Santhapparay, S"lnvestment in Information and Communication Technologies (ICT) and Its Payoff in Malaysia," Perspectives on Global Development and Technology (4:2), 2005, pp. 147-167.

Mbarika, V. W. A., Okoli, C., Byrd, T. A. and Datta, P. "The Neglected Continent of IS Research: A Research Agenda for Sub-Saharan Africa," Journal of the Association for Information Systems (6:5), 2005, pp. 130-170.

Morawczynski, o. and Ngwenyama, o. "Unraveling the Impacts of Investments in ICTs, Education and Health on Development: An Analysis of Archival Data of Five West African Countries Using Regression Splines," Electronic Journal on Information Systems in Developing Countries (29:5), 2007, pp. 1-15.

Ngwenyama, o., Andoh-Baidoo, F.K., Bollou, F. and Morawczynski, o. "Is There A Relationship Between ICT, Health, Education and Development? An Empirical Analysis of Five West African Countries from 1997-2003," Electronic Journal on Information Systems in Developing Countries (23:5), 2006, pp. 1-11.

Oulton, N. "ICT and Productivity Growth in the United Kingdom," Oxford Review of Economy Policy (18:3), 2002, pp. 363-369.

Palvia, P. "Key IS Management Issues: Need for an International Research Program," Journal of Global Information Technology Management (9:2), 2006, pp. 1-4.

Qiang, C. Z. and Pitt, A. "Contribution of Information and Communication Technologies to Growth," The World Bank Working Paper Series (24), 2004, pp. 1-28.

Rao, M., Earls, T., and Sanchez, G. "International Collaboration in Transorganizational Systems Development: The Challenges of Global Insourcing," Journal of Global Information Technology Management (10:3), 2007, pp. 52-69.

Salford Systems, MARS User Guide (C), Retrieved February, 10, 2011 from www.emc.ncep.noaa.gov/research/Manuals/MarsU serGuide, 2001.

Samoilenko, S. and Osei-Bryson, K-M. "An Exploration of the Effect of the Interaction Between ICT and Labor Force on Economic Growth in Transition Economies," International Journal of Production Economics (115:8), 2008a, pp. 471-481.

Samoilenko, S. and Osei-Bryson, K-M. "Determining Strategies for ICT to Improve Efficiency in the Production of Revenues: An Empirical Investigation in the Context of Transition Economies Using DEA, Decision Trees, and Neural Nets," Journal of Global Information Technology Management (II :4), 2008b, pp. 56-75.

Samoilenko, S. and Ngwenyama, o. "Understanding the Human Capital Dimension of ICT and Economic Growth in Transition Economies," Journal of Global Information Technology Management (14:1), 2011, pp. 59-79.

Servon, L. Bridging the Digital Divide: Technology, Community, and Public Policy, Malden, MA and Oxford: Blackwell, 2002. 
Shiraz, F. "The Impact of ICT Expansion on Promoting Democracy and Economic Freedom in the Middle East (1995-2005)," Unpublished Doctoral Thesis, University of Cape Town, South Africa, 2010.

UNDP "Concept and Measurement of Human Development, Human Development Reports," Retrieved March 20, 2011, from http:hdr.undp.org/en/reports/global/hdr199o/.

UNDP. "Human Development Index Reveals Development Crises, Human Development Reports," Retrieved September 15, 2010, from http://www.undp.bg/uploads/documents/ 1162_536_en.pdf, 2003.

UNDP "The Millennium Development Goals, Human Development Reports," Retrieved March 20, 2011, from http://unstats.un.org/unsd/mdg/Resources/Static/Products/Progress2006/MDG Report2006.pdf, 2006.

Weber, G., Batmaz, I., Koksal, G., Taylan, P., and Yerlikaya-Ozkurt, F. ." CMARS: A New Contribution to Nonparametric Regression with Multivariate Adaptive Regression Splines Supported by Continuous Optimisation," Journal of Computational and Applied Mathematics, (105), 2010, pp. 1-33.

WITSA, Digital Planet 1998: "The Global Information Economy", Arlington, VA: The World Information Technology and Services Alliance, 1998.

WITSA. Digital Planet 20o8: "The Global Information Economy", Arlington, VA: The World Information Technology and Services AllianceWolde-Rufael, Y. 2007. "Another Look at the Relationship Between Telecommunications Investment and Economic Activity in the United States," International Economic Journal (21:1), 2008, pp. 199-205.

Felix Olu Bankole is a Lecturer/Coordinator of IT Infrastructure and Application Management Programme at the University of the Western Cape. He holds a PhD in Information Systems from the University of Cape Town. He is also a Research Associate at the Centrefor IT and National Development in Africa (CITANDA) at the University of Cape Town. His current research interests are in the area of JCT and national development, Data Mining and Business Analytics.

Kweku-Muata Osei-Bryson is Professor of Information Systems at Virginia Commonwealth University. He has also worked as an Information Systems practitioner in both industry and government. He currently does research in various areas including: Data Mining, Expert Systems, Decision Support Systems, IT \& Productivity, Information Systems Outsourcing, and Multi-Criteria Decision Analysis. He has published in various leadingjournals including Information Systems Journal, Journal of Global Information Technology Management, Information Sciences, Information and Management, Information Systems Frontier and European Journal of Operational Research.

Irwin Brown is a Professor in the Department of Information Systems (IS) at the University of Cape Town. Irwin's research interests relate to issues around IS in developing countries contexts. He has published in outlets such as the European Journal of Information Systems, Communications of the AIS, Journal of Global 
Information Technology Management, the International Journal of Information Management and Electronic Journal of IS Evaluation 